\title{
Understanding structures and practices of meaning-making in industrial networks
}

Sid Lowe, Visiting Researcher, Universidad de Sevilla // University of Seville Av. Ramon y Cajal, 1. E41018, Sevilla, Spain drsidlowe@yahoo.co.uk

Michel Rod*, Sprott School of Business, Carleton University, 1125 Colonel By Drive, Ottawa, Canada, K1S 5B6, Tel: (613) 520-2600 ext. 6327, Fax: (613) 520-4427 michel.rod@carleton.ca

Ki-Soon Hwang, Kingston University Business School, Kingston University Kingston-Upon-Thames, Surrey, KT2 7LB, Tel: ++44 (0)208 417 5652, Fax. 02084177026 K.Hwang@kingston.ac.uk

*Corresponding author 


\title{
Understanding structures and practices of meaning-making in industrial networks
}

\begin{abstract}
Purpose: To propose an approach for exploring industrial marketing network environments through a social semiotic lens.

Design/methodology/approach: This conceptual paper introduces social semiotic perspectives to the study of business/industrial network interaction.

Findings: We describe how structures of meaning derived from a cultural history of signification and interpretive processes of meaning in action are co-determined in social semiosis. We emphasise the meaning of environments using this social semiotic approach, leading us to explore the idea of the 'atmosemiosphere' - the most highly complex business network level, in illustrating how meaning is made through structuration between structures of meaning and their enactments in interactions between actors within living business networks.

Practical Implications: Figurative language plays an important role in the structuration of meaning. This facilitates establishing plots and, therefore, in the actors' capability to tell a story, which starts with knowing what kind of story can be told. By implication, the effective networker must be a consummate moving 'picture maker' and to do so, she must have competences in narrative, emplotment, myth-making, storytelling and figuration in more than one discursive repertoire.

Originality/Value: In employing a structurational discourse perspective informed by social semiotics, our original contribution is a 'business networks as discursive constructions' approach in that discursive nets, webs of narratives and stories, and labyrinths of tropes are considered just as important in constituting networks as networks of actor relationships and patterns of other activities and resources.
\end{abstract}

Keywords: structurational discourse, social semiotics, atmosemiosphere, B2B Networks

\section{Conceptual paper}




\section{Introduction}

The relationship 'atmosphere' is a key concept in business-to-business marketing and specifically in the interaction approach to industrial marketing (Ford \& Håkansson, 2006; Cantù, Corsaro, Fiocca, \& Tunisini, 2013; Ford \& Håkansson, 2013). Atmosphere tends to comprise the more nebulous features of interaction and communication in the $\mathrm{B} 2 \mathrm{~B}$ environment. Following Hedaa and Törnroos (2007), we believe that there is room to develop the 'atmosphere' concept further by exploring the network as a key metaphor in the introduction of the idea of the 'atmosemiosphere' - what we define as the semiotic environment where the interrelation of parts in an organized whole i.e., between structures and behaviours, is brokered through discourse. Table 1 provides an outline comparison between atmospheric and atmosemiospheric conceptions.

\section{INSERT TABLE 1 ABOUT HERE}

We view this paper as being complementary to recent work published in this journal that has great potential to advance business-to-business (B2B) marketing in terms of its future research directions e.g., Cederlund's (2014) call for using managerial relevance as a method to forward B2B marketing theory, Todd, Javalgi and Grossman's (2014) organizational ecology approach to the business environment, Raskovic’s (2015) economic sociology perspective applied to the activity-resource-actor (ARA) interaction model, IvanovaGongne’s (2015) individual sense-making in business relationships, and Ryynänen, Henttonen and Salminen’s (2015) collective cognitive structures in business networks. 
This conceptual paper is grounded in a social semiotics perspective which emphasises “semiotic resources”. These are the 'signs' that actors use to construct meaning. This process of meaning-making is situated and contextual, with the meaning outcomes dependent upon the history of meaning of a sign, its ‘affordances’ or potential meaning, the actors' knowledge and interpretation of the meaning(s) of the sign and the influence of their motives and interests in the making of meanings. What we will gradually propose is that the 'atmosemiosphere' concept can be seen as a label for the outcomes of relations between the theoretical semiotic potentials of objects and their actual interpretation in practice/action. We offer this paper in an effort to theorize some assumptions of business interactions in industrial marketing and management. Thus, our overall objective in this paper is to propose an approach for exploring industrial marketing network environments through a social semiotic lens and from a Giddensian discourse structurational perspective, where actors are both constrained and enabled by existing structures of signification, legitimation and domination. We specifically associate semiotics with industrial network research i.e., industrial networks are organized in networks that are relational in terms of the actors, activities and resources that constitute them - atmosemiospheres. We propose that their environment is constituted by ubiquitous signs in addition to material factors. These signs are also organized relationally and predominantly through indirect analogical association. All texts are encoded by reference to other texts. Nothing, in other words, is ever really new. Semiotic signs also are transmitted explicitly but mostly tacitly. As a result, understanding of the atmosemiosphere enables a better opportunity to manage it by realizing that such management will differ from how the material counterpart to signs is managed.

The paper involves a systematic review of the relevant IMP, industrial network and semiotics literatures and is directed primarily at IMP researchers but secondarily to those business-to-business (B2B) and network researchers not necessarily familiar with the IMP 
oeuvre. The focus of the study is on how inter-connected modern myths influence what is believed within groups and how these images affect how group members use such mythologies to 'see what they believe'. This paper therefore, seeks to start with a description of the complex, dynamic, symbolic environment by focussing first on social semiotics, then the context of business networks followed by the symbolic and metaphorical aspects of organizational discourse and on the use of myths and metaphors as significant elements, thus adding and equalizing analysis of discursive interaction to the existing work on relational and cognitive interaction. This is then followed by a deeper discussion of the 'atmosemiosphere' and its characteristics before illustrating the implications for industrial marketing research and practice.

\section{Social semiotics}

Social semiotics is a branch of the field of semiotics which tries to explain meaning-making as a social practice by exploring the implications of the fact that the 'codes' of language and communication are formed by social processes (Thibault, 1991; Van Leeuwen, 2005). In other words, signs are not causal determinants of meaning but resources from which meaning is made. Social semiotics tries to account for the variability of semiotic practices by illustrating how individual creativity, changing historical circumstances, and new social identities and projects can all change patterns of usage and design (Hodge \& Kress, 1988). From a social semiotic perspective, rather than being fixed into unchanging 'codes', signs are considered to be resources which people use and adapt (or 'design') to make meaning. It is thus, the study of the social interaction of meaning-making, and of the power of human processes of signification and interpretation (known as semiosis) in shaping individuals and societies whether visual, verbal or aural in nature (Thibault, 1991). Different systems for meaning-making, or possible ‘channels’ (e.g. speech, writing, images) are known as semiotic 
modes. Semiotic modes can include visual, verbal, written, gestural and musical resources for communication. They also include various multimodal ensembles of any of these modes (Kress \& van Leeuwen, 2001). Social semiotics includes the study of how people design and interpret meanings, the study of texts, and the study of how semiotic systems are shaped by social interests and ideologies, and how they are adapted as society changes (Hodge, 1988; Kress, 2009).

Semiosis is more apparent when 'virtual' and 'vicious' circles are evident in B2B relationships. When for example, a buying company has underlying assumptions and images of a supplier as being reliable and trustworthy, these assumptions are sustained by narratives and stories of trust. Consequent artifacts, such as credit lines, become symbols of trust and the supplier reciprocates with reliability and meeting expectations for delivery etc. In the supplier organization, narratives and stories sustain this behaviour and the buying company is identified through metaphors and other tropes as partners (marriage metaphor), 'key' accounts (physical lock metaphor) or as the lifeblood (embodied metaphor) etc. Symbols of trust, tropes of trust and trustworthy behaviour are likely to re-confirm the initial assumptions of the trustworthiness of the supplier in the buyer. This kind of virtuous circle, however, can easily turn into a vicious circle of mistrust by accidents, failures and the saying or doing of the 'wrong thing'. Given that the main task of social semiotics is to develop analytical and theoretical frameworks which can explain meaning-making in a social context (Thibault, 1991), we develop the 'atmosemiosphere' concept by drawing on social semiotics and structural discursive perspectives to explore signified interaction in industrial networks.

\section{Network environments}

We propose the 'atmosemiosphere' as an appropriate construction of the environment and do so through a structurational view of discourse because it better enables us, as researchers of 
business interaction, to uncover the features of discourse that tend to be unconscious or tacit. This approach can provide access to actor's practical consciousness - what they 'know' but can’t express explicitly except through their discursive actions. This is because from a discourse structurational perspective, actors within the atmosemiosphere engage in purposive communication action that can achieve manifest outcomes, that reflect socially constructed reality and which has the potential to change entrenched social structures (Heracleous \& Hendry, 2000). What this view of the environment embraces, is that the notions of time and context are very important and it takes us in a direction away from attempting to generate grand theories of business interaction that transcend context.

This notion of the environment encompasses a perspective involving the combined influences of process, pattern, language, communication and interpretation, and embodied structures. Our focus is not on B2B networks viewed through conventional systems thinking with hierarchies and boundaries but rather at a higher level of complexity where the B2B network atmosemiosphere's emergence is more 'holographic', non-linear and nonhierarchical (Boje, 2008). From social exchange, network theoretical, social semiotic and structurational discourse perspectives, the atmosemiosphere contains the texts, artefacts, images, meanings and institutions or signified 'atmosphere' in which multiple interactions occur.

From an IMP/Industrial networks perspective, in the realization of atmosemiospheres, actors, activities and resources are embedded in the dynamic relation between signifiers (their communicated representations) and signified (the sense made of the representation in the minds of the actors). Because actors, activities and resources, 'inhabit' an environment of inter- related signs, every aspect of their meaning is subject to the atmosemiosphere directly or implicitly. We view business networks as symbolically constituted where language/discourse plays a central role as the medium for shared understanding in the 
creation and maintenance of network structures and images of business relationships. In introducing the notion of the atmosemiosphere; involving dynamically inter-related symbols, intertextual analogical reasoning, connotations and adaptive systems of tropes such as metaphors, narratives, stories etc., we are exploring, therefore, Barthes' (1974) notions of discourse as constituted by multiple hermeneutics involving interwoven codes, myths and symbols arranged in dynamic webs of interaction and Giddens' structurational view of discourse, where actors are both constrained and enabled by existing structures of signification, legitimation and domination. The atmosemiosphere is therefore, a network of images and semiotic relationships. Meaning, which is the principal product of the atmosemiosphere, has many possible manifestations because of the many possible combinations of its symbolic elements. Which meaning becomes the received wisdom for a time in any place is, we will argue, a consequence of power play processes reflecting whose meaning is repeated most often and/or whose myths become accepted truths, or perhaps who is better in the use of rhetoric, discourse and argument (Watson, 1995) given that "dominant meanings emerge from the power-laden nature of organizational contexts" drawing upon "the discursive practices and rhetorical devices that are deployed in these struggles around meaning” (Grant \& Hardy, 2004, p. 5).

We depict meaning as a consequence of maintaining and renewing itself by regulating its composition and conserving its boundaries. The self-making is a result of complex, interacting social representations arising from beliefs. Beliefs, in turn we propose, are constituted by evolving and prevailing myths and folklores, fantasies, values, assumptions and other products of human imagination. Conveying these beliefs are 'discourses' (language, communication, information and power/knowledge) and the projection of meanings is constituted by narratives, stories, metaphors and other 'tropes', analogical reasoning as well as other symbolic devices. How inter-connected modern myths influence 
what is believed within groups and how these images affect how group members use such mythologies to 'see what they believe' is a focus of this paper.

Environments, in Giddensian structuration, follow the logic of the duality of agency and structure and are therefore made in discourse through action which is both a medium of structure and constituted by it. Thus, industrial network researchers need to recognize that business environments are mutually-constituted by a surface level of discursive action and a deeper level of discursive structures mediated by actors' interpretive schemes located in their practical consciousness. What is said is framed structurally by a history of what has already been said but what can be said is afforded agency according to the particular situation. Our argument is that contemporary business networks are not unlike traditional, pre-modern cultures in that they are also subjectively immersed in mythologies and folklore. The main difference is that modern mythologies are ideologies that disguise themselves for rhetorical effect; they are myths pretending to be non-myths. The symbolic glue that ties the mythscape together (we are using a metaphor to describe metaphor now) is the symbolic, intertextual combination of tropes (Küpers, 2013). Modern myths are therefore primarily constituted by modern metaphors and other tropes. All cultures, no matter how objective or rational they might believe themselves to be, are creative image-making networks of embodied, discursive and cognitive sense-making. All cultures (including modern business networks) are, from this perspective, inventing and projecting their World rather than simply discovering it. In the invention of the World, the inventors whose 'translations' of it are accepted come out on top and those whose inventions are ignored are marginalized and silenced. The essential position of this paper is that myths can be regarded as "ideology[ies] in narrative form” (Bathurst \& Monin, 2010, p. 262) that are used by practitioner networks to configure meaning and establish identity positions. We will illustrate how the atmosemiosphere of modern myths is connected through stories and metaphors (and other 
tropes) through discursive webs. We will also argue that most meaning and the decisions that are made based upon this meaning are influenced by tacit, analogical, symbolic, and dynamic 'received wisdoms' where influential business 'elites' employ individual agency and discursively draw upon the atmosemiosphere to further their own agendas.

\section{Symbolic and metaphorical aspects of organizational discourse}

There has been ongoing and growing interest in the study of metaphor within organizational research (Cornelissen, Oswick, Christensen, \& Phillips, 2008) and since the late 1970s, there has been a great deal of attention paid to the symbolic and metaphorical aspects of organizational discourse and the role that language plays in mediating shared understanding in the development and ongoing maintenance of organizational structures (Heracleous \& Hendry, 2000). The premise of this paper is that this can and should be extended outside any focal organization to the context of inter-organizational interaction in networks. Environments and behaviours, from this perspective are structurated through the mediation of discourse. Environmental aspects are enacted in behaviour and the principal medium of this structuration process is discourse. Employing Giddens' (1984) structuration as a principal theoretical resource means that "discourse is viewed as a duality of communicative actions and structural properties, recursively linked through the modality of actors' interpretive schemes” (Heracleous \& Hendry, 2000, p. 1251) so that the subject can be seen as both constrained and enabled by structures differently in different contexts. Being both enabling and constraining, these structural features of discourse are employed in particular contexts in order for actors' opinions, ideas, or argumentations to be seen as legitimate and worthy of attention. Discursive structural features can be used as a resource for effective argumentation characterized by a 'seeming' probability i.e., what actors in a social context view to be the true and not necessarily what is true. Here 'practical consciousness' becomes the key 
modality to understand because it translates structures and action in both directions. Schemas/scripts are the most readily accessible manifestation of practical consciousness and they operate in contexts reflecting the heterogeneity of both structures and actions.

Applying this to a business network viewpoint means 'interaction' is not only substantive (Ford, Hakansson, Gadde, Snehota, \& Waluszewski, 2009) but also hugely symbolic and discourse is its main resource. Ours is an attempt to further develop this concept of interaction. Network actors' discursive activities are translated through their resources involving schemas and practical consciousness to affect and be affected by structural influences such as power, institutions, values, and other facets of the 'environment'. Discourse structuration is a social semiotics method providing a principal interpretive vehicle for the two-way translation between the environment and its enactment in everyday practice. Elements in the environment, such as power in the political environment, markets and competition in the economic environment, institutions in the social environment and values in the cultural environment are 'made' sense through enactment processes with discourse being the principal vehicle for this making.

Conventions or orders of discourse exist in networks and embody ideological structures that reflect and enforce power structures within the speech community. Discursive orders, therefore, delineate within some degree of flexibility, in any given context, what can be said, who should be saying what and when, what the subject positions or roles of the actors require and what forms of address are expected. Greater constraints are imposed on the powerless than the powerful but all are subject to some constraints in some form. Such constraints paradoxically enable enactment, behaviour and action. Without these fuzzy discursive rules that broker structures and actions, structuration, enactment and behaviour would be disabled. Without the scene as set by forms and orders of discourse, the extended 'plays' of everyday interaction would be impossible. This interpretive view also recognizes 
that some degree of agency enables change and accepts that the management of consent is not uncontested. Structures are not immutable and structural conditions. Structures such as power inequalities, can at times be modified in action and through discourse. However structures do produce consistent responses through discourse on behaviour generally when they are forceful and combined. Powerful interests, bureaucratic institutions, rationalist epistemes, and Western values such as individualism can in combination secure structural forces through discourse in enactment and behaviour. As orders of discourse are networked and interconnected, structural forces are constructed mostly through indirect means such as allusion, figures of speech, metaphors, narratives and other tropes. The power of discourse to effect structural interests is, from this point of view, tacit and hidden in symbolic 'webs of significance' (Geertz, 1973). What we describe as 'atmosemiospheres' is the semiotic environment where the structuration between structures and actions is brokered through discourse and social signification.

The use of language in business networks can alter their meaning, knowledge, rules, boundaries and identities. Business networks as living systems are thus paradoxically dependent and autonomous, producers and products of themselves, creators of and created by their environments. These ambiguous processes involves actors influencing others and allowing others to have influence (Ford \& Saren, 1996) and other curiosities, such as identifying others in their own image and identifying themselves as a reflections of others. In a B2B context, being both reactive and proactive in relationship management is as much about being managed as it is about managing (Ritter, Wilkinson, \& Johnston, 2004), where networking happens in ‘a space of paradoxes’ (Håkansson \& Ford, 2002).

\section{The role of myths and metaphors in meaning-making}


From a social semiotic viewpoint, sense-making involves intersubjective creations of reality through ongoing interaction with others which construct and communicate meaning "and of the essential role of language in enabling us to reflexively describe the social world around us, for instance, through telling stories about some aspect of it” (Fuller \& Lewis, 2002, p. 320). We adopt nominalist assumptions that, in interaction, people largely 'see what they believe' and that through the meanings/beliefs they create, emerge the realities that they intersubjectively project. As a result, we propose that an important focus of research is to explain how 'discourse' affects intersubjective sense-making through myth-making, how meanings arise, how beliefs come to be formed and who benefits most from them.

We argue that knowledge created through emergent meaning is a complex hermeneutic process and that in such sense-making, indirect associations, figures of speech and analogical reasoning are pervasive in the constructions and maintenance of mythologies that we come to project as reality. The creation of meaning relies upon communication and language as the most influential vehicles of this process of projection. The process is complex but because of the ubiquity of figurative language, meaning creation is more heavily dependent upon analogical than literal meaning. The unknown or new experience is usually co-opted into an already known subjective meaning set, or web of connotations. So, for example, through the use of metaphor and 'conceptual blending' (Fauconnier \& Turner, 2008), new knowledge is created incrementally through a concocted blending of old and new images. New events, therefore, are usually co-opted into present mythologies. This is illustrated in Elliot, Xiao and Wilson’s (2015) ethnography where a Chinese businessman interacting with his American associates at a Chinese restaurant engage in a discussion about the statue of a dragon at the restaurant's entrance. The former toasts their relationship highlighting the dragon's presence representing royalty, power, strength, and good luck, which he notes as important to their business relationship that involves significant 
investment. The Americans note that the dragon represents evil in American culture and that a crown would be more appropriate. The ensuing discussion involves comparing, contrasting and sharing of information resulting in a gradual understanding, reflection and evaluation of the value of their business relationship. The compromise is a dragon wearing a crown as a symbol of their relationship. In this example, the dragon is the presentation space and the reference space is "power/good luck" or "evil” depending on whether a Chinese or American individual is making the reference and the crown-wearing dragon represents conceptual blending. In this instance where incoming information diverges from that predicted by the contextually evoked frame, 'frame shifting' has occurred whereby semantic reorganization enables the American to embed the meaning of power and good luck in the dragon rather than evil. These mixing of metaphors are examples of 'polytropy'. They involve sharing images that can lead to shared identities. They can form a critical form of emplotment of joint identity as narratives of you and I are converted into stories of us and symbolization of 'we'. Such storying has to be told and retold involving both stability and change in the identity. Much of this dynamic involves shifts in social capital, cultural capital and economic capital in the relationship field, its enactment through the habitus (or members' sense-making resources for the 'rules of play') of the actors and its manifestation as identity and other symbolic capital (Bourdieu, 1986). If significant changes occur in related and overlapping fields, such as Power, then the story of the relationship has to be retold and the metaphors may have to be re-mixed.

Myths are elements of fantasies that can turn reality into a coherent whole and organize and express our embodied emotions in narrative form (Bloom \& Cederstom, 2009). They are multi-variant, often repetitive narrative guides to meaning, for action and the establishment of fleeting 'truths' within cultures (Munro \& Huber, 2012). Barthes (1972) views modern mythologies as ideology constituted by networks of connotations of meaning 
connected through metaphor and other tropes. To be effective, the myth must make us understand something and impose it whilst disguising its ideological nature through naturalization (Barthes, 1972). Often enduring mythical 'grand' narratives constitute a type of closure that expresses and maintains the control or 'governmentality' (Foucault, 1997) of dominant ideologies and power stratifications (Mumby, 1987; Brown, Humphries, \& Gurney, 2005). So, for example, when someone asserts and is unchallenged by saying 'you can't beat the market', the market (myth) is valorized as unbeatable because to try and beat it is unnatural, meaningless and/or futile. Myths serve to perpetuate identities by 'passing down' projections to successive generations the resources, prized meanings, essences of common sense, core ideals and tacit expectations of what it means to be one of us. In myth, therefore, we establish where we have come from, who we are, and how we should maintain the fiction of 'us'. Myths are, therefore, powerful in creating identities, meaning and in justifying actions. In business marketing, the markets-as-networks approach focuses on 'market making' through co-creation of markets and their representations which demonstrates that the symbolic struggle to represent markets is one infused with power and self-interest (Rinallo \& Golfetto, 2006; Kjellberg \& Helgesson, 2006; 2007). In semiotic terms, markets are shaped by constant battles of performativity of competing, multiple and sometimes incompatible mythologies.

We propose the notion of the atmosemiosphere as a shorthand or proxy concept for a complex and dynamic system of projected myths, fantasies, images and meanings that constitute and are constituted mostly through 'never-ending stories' (Håkansson \& Waluszewski, 2013), figuration and analogical reasoning, 'hinting', alluding and other indirect communicative associations within business network interactions. In atmosemiospheres, meaning changes in different contexts according to different languages used and action takes place within the labyrinth of images and according to the somewhat 
slippery, uncertainties of meaning-making in diverse symbolic interactions. The atmosemiosphere is a concept that derives from the introduction of discourse and narrative into the analysis of B2B networks (Lowe, Ellis, \& Purchase, 2008).

Effective discourses and stories have to navigate between stability and change of meanings, between tacit and explicit understandings between different types of talk, between discursive and non-discursive (such as embodied) types of sense-making and temporal and atemporal sense-making. Makkonen, Aarikka-Stenroos, and Olkkonen (2012) propose that different levels of narratives correspond to network process structural contexts, presented as two dimensions; vertical at various levels and horizontal as time. It is the liminal, projected, holographic, autopoietic and 'polyphonic' character and multiplicity of discourse that makes it harder to 'pin down' than relational, behavioural and cognitive aspects of networking and which also makes the paradigmatic assumptions often applied to these other aspects inappropriate for discourse analysis. In the remainder of this paper, we will examine some of the challenges (and possible solutions) posed for discourse analysis of complex atmosemiospheres in the context of B2B marketing research in more detail. We will then explore some prioritized implications for practice and research. Before this, we explore mythologies in more detail by outlining descriptions of intertextuality, tropes and narratives, which are all key elements of atmosemiospheres and review their use in industrial marketing research.

\section{Key elements of atmosemiospheres}

Atmosemiospheres are an understanding of the atmosphere environments of networks when taking into account the importance of rather paradoxical semiotic exchanges and complex communicative interactions between structures of meanings and their enactments. In the atmosemiosphere nothing is ever fully structured or fully processsual and it contains both 
homogenous meanings and heterogeneous contextual meaning. The atmosemiosphere - a semiotics environment of panrelational signs or semiosphere is heterogeneous and signs operate in this environment differently in different contexts. Therefore signs cannot be regarded as universal or decontextual, homogenous or stable. We propose three notions that are key discursive enablers in the constitution of atmosemiosheres; namely intertextuality, tropes and narratives.

\subsection{Intertextuality}

Prevailing myths are ideologically powerful mostly because they gain passive, tacit acceptance by networks of analogical reasoning, which means that they often 'go without saying'. All texts are encoded by reference to other texts. Nothing, in other words, is ever really new. When meaning is exchanged in interaction, much of this exchange is projected through indirectness and association (Tannen, 2010). Speaker and listener, author and reader are referencing, referring, alluding or relating to an existing semantic or connotative web created and accepted in prior conversations and readings. Communication of necessary consequences of meaning (entailments) involves abduction, involving meaning transfer through analogy and symbolic connotation. Tannen (2010) suggests that notions such as Bateson’s (1979) ‘abduction', Freidrich’s (1991) ‘polytropy’, Becker’s (1995) 'prior text’ in languaging and Bakhtin’s (1986) ‘dialogicality’ are all conceptualizations of intertextuality. Intertextuality, therefore, involves the pervasive discursive practice of picturing through indirectness by 'hinting' in interaction or picturing by comparison and accomplishing meaning through association or allusion. Tannen (2010) explains that for these intertexuality theorists, the meaning speakers convey from words in interaction derives from how those words have been previously used. Meaning is accomplished mostly tacitly and indirectly through hint-laden allusions. 
The implication is that through interaction, people mostly invent or frame their present and future 'pictures' of reality tacitly by indirect reference to an established semantic web of previously framed, fictional, invented pictures of the past. Meaning in interaction arises in semiotic terms between differences in signifiers and is based upon highly tacit, commonsensical, historically and culturally-dependent 'second-order' projected meanings carried through time in discourses and interpreted through evolving interpretive schemata in present interactions. Jian (2011) argues that the key processes here are 'articulations' involving discursive struggles in interaction over articulating multiple and competing layers of meaning.

Intertextuality, for example, is pervasive and institutionalized in academic speech communities and all communities of lexical practice. Analogical expressions can capture or infect the beliefs within academic communities through viral intertextual exchanges and can quite quickly “end up as an ideology that is taken for granted” (O’Malley, Patterson, \& Kelly-Holmes, 2008, p. 169). From this point of view, dynamic meaning is an outcome of battles won to assign a discourse/myth or combination of discourses/myths as explanatory to conditions of circumstance and situation, identities and consequences of action. Competing narratives can often be ascribed to different groups within organizations (Brown \& Humphries, 2002) and, we would expect, different interest groups of actors within business networks.

\subsection{Tropes}

Tropes are ubiquitous, pervasive ‘figures of speech' for creating meaning in context where meaning is accomplished through poetic imagination in terms of 'second order' intertextual projections (describing things in terms of other things comparative, contiguous or opposite to them). Contrary to some popular opinion, tropes are much more than just 'ornamental 
language'. They are integral to conceptual blending devices of meaning-making that allow for both cultural perpetuation and innovative novelty in the processes of social constructions of reality using conceptual frames during interactions (Fauconnier \& Turner, 2008). Metaphors along with other tropes enable humans to think and talk about conceptual abstractions such as knowledge, time, relationships, organizations etc. Metaphors are never ideologically neutral because their focus "always highlights some elements of a phenomenon while hiding others” (O’Malley et al., 2008, p. 169). Metaphor has thus been positioned as a cognitive linguistic, psycholinguistic, literary organizing principle used to construct conceptual understanding (Denny \& Sunderland, 2005). This supports metaphor as having a constitutive role in myth and meaning-making.

As 'figures of speech', tropes are the key discursive means by which indirectness of analogical reasoning, comparison and connotative associations are projected. They are pervasive in discourse and litter all communication. In this paragraph, we highlight their use in our own text using italics in order to make the particular point about their ubiquity. Tropes such as metaphor, metonymy, and synecdoche are the most common, with irony often described as the fourth principal trope (Putnam, 2004). In any text, you normally don't have to read very far before a metaphor appears.

Metonyms and synecdoche are 'syntagmatic' tropes. They are signifiers of combinations or chains of meaning that connect 'parts' and 'wholes'. Metonyms (name changes) are rhetorical strategies usually referring to things through characteristics commonly attributed to them or where the whole stands for its constituent parts (Putnam, 2004). In industrial marketing contexts, the expression 'smokestack industries' is idiomatic metonymy for basic technologies as compared to 'high-tech' (another metonym) industries. Synecdoche involves using part for the whole or vice versa. The most ubiquitous synecdoche is 'the 
market', because it is a whole used to substitute for the parts (particular 'buyers' or 'customers').

From the perspective of 'pictures' in business networks, a holographic metaphor affords the realizations that pictures are made of signifiers and mostly of words that carry a history of meanings, figurative language games and images and that these are mostly indirect, tacit, interconnected, unmanageable and culturally-embedded projections that look different from different vantage points. What emerges as 'truth' is, from this perspective, the product of a history of complex, interconnected fictions that change as you 'zoom in' or 'zoom out' (Nicolini, 2009).

\subsection{Tropes and narratives in industrial marketing research}

Metaphors are influential and pervasive but often largely invisible or tacit within management (Morgan, 1986) and marketing discourse and thought development (Hunt \& Menon, 1995). Often this results, within academic networks, in naïve representations and perpetuation of the dominant paradigm of objectivist realism/scientism. In B2B research, Ford and Håkansson (2006) have discussed the importance of 'theoretical metaphors' or stereotypes such as 'markets' or 'supply chains' in forming actors' subjective interpretations of networks, interactions and relationships. Following on from the use of 'atmospheres' and 'episodes' in the prior model, metaphors such as marriage (Dwyer, Schurr, \& Oh, 1987; Johnston \& Hausman, 2006; Stoltman \& Morgan, 2002; Celuch, Bantham, \& Kasouf, 2006), maps and pictures (Geiger \& Finch, 2010: Lowe, Ellis, Purchase, Rod, \& Hwang, 2012), drama (Lowe, Purchase, \& Ellis, 2012), dance (Wilkinson \& Young, 1994; Wilkinson, Young, Welch, \& Welch, 1998), waves as relationship dynamics (Edvardsson, Kowalkowski, Strandvik, \& Voima, 2014), neurological networks (Cunningham, 2007) and network 'pictures’ (Ford, Gadde, Håkansson, \& Snehota, 2003; Ford \& Redwood, 2005; Mouzas, 
Henneberg, \& Naudé, 2008; Henneberg, Naudé, \& Mouzas, 2010) have been tropal representations recognized and adopted, with varying degrees of 'uptake' by the group or parts thereof, over time.

The implication is that metaphors enter a cycle of resonance, viral acceptance, popularity, lexicalization/idiom, entropy of plausibility, decline and death followed by replacement and repetition. For O’Malley et al. (2008), the relationship metaphor is in terminal decline and need of drastic re-invention. O’Malley et al. (2008, p. 182) assert the need for marketing academics "to acknowledge and problematize the lexis of their professional discourse community and the lexical and ideological constraints within which their writing takes place”. Lowe et al. (2008, p. 296) similarly suggest that "marketing research more generally, is orientated not just by its language, but more importantly by how it uses language to describe constructs such as relationships, interaction, actors, etc.”.

\subsection{Narratives and storytelling}

Metaphors and narratives/stories are both tropes of organizational communication that play a significant role in organizational sense-making and identity (Brown, Colville \& Pye, 2015; Gabriel, Geiger, \& Letiche, 2011). Business relationships within networks are narrated through episodes of dialogical interaction and this narration is converted to story through plots of trust and commitment. Sense is made when a story co-ordinates narrative rationality and connects a plot with characters (Cunliffe \& Coupland, 2012).

To be effective, narrative plots often rely upon the poetics of tropes and particularly metaphor. So, in picturing the world, there are shared repertoires (Potter \& Wetherell, 1987) making pictures that move by using narrative, plots, stories, myths, metaphors and figurative language. These repertoires are consistently repeated, evolving stories or myths that serve as interpretive cine-cameras in moving picture-making. They often act as chapters do in a novel; 
in organizing a more thematic and bigger picture that has a moral and political message. Stories are a principal way in which life's lessons, values and world views are conveyed within a culture (Benham, 2007). In organizations, narratives sustain a living folklore about the identity, purpose, history and character of the firm (Gabriel, 2000; 2004). This often produces self-reinforcing blind spots that become a potential source of organizational inertia (Geiger \& Antonacopoulou, 2011). The unpredictable consequences of the combination of narrative/story and metaphor mean that re-enforcement and dislocation are both possible as, for example a metaphor can be used to validate or destroy a story (Riad, 2011). From this perspective, discourses change what is heard depending upon network position and this will inevitably create multiple perspectives and applications of how to interpret plots (Kronberger, Clegg, \& Carter, 2006). Narratives make sense of space and time through the relation within signs between signifiers. Time and space are dealt with semiotically through narrative and storytelling. Semiosis is completed with the use of analogical reasoning, which concerns the relational connections between signs themselves, their inter-textually and panrelational meanings. For example, "the deal fell through with the Chinese” is a narrative. 'The Chinese' is a synecdoche (a trope like a metaphor) used as a signifier to identify one party in the mind (the signified). "The deal fell through with the Chinese because our accounts department failed to pay a security fee on time” is a story because a plot is added and a villain or antagonist is identified (the accounts dept. is another synecdoche). Sense is made in space and time, what happened is added to by why it happened and for the moment believability (known as verisimilitude in narrative analysis) is credible.

One of our main propositions in this paper is that the use of metaphors and tropes, along with other aspects of discourse and particularly narratives and storytelling in business networks, is vast but their role is under-researched. We, therefore, would like to encourage industrial marketing researchers to revisit their unchallenged 'tropes' and metaphorical 
assumptions and reflexively interrogate the subliminal assumptions that they support. By 'thinking about thinking'; specifically about how the use of these tropes helps B2B researchers to explain, interpret, categorize and summarize (Woodside, 2008) in personally introspective, autoethnographic accounts of doing research (Holbrook, 2005; Woodside, 2006), the hope is that greater attention is paid to methods that uncover deep metaphors (or to methods that reveal unconscious myths (Martin, 2010; Martin \& Woodside, 2011) and the unconscious frames that govern and guide our thoughts as researchers through ways that allow us to gain deeper insights about linkages between our implicit and explicit thoughts (Zaltman, 2008; von Wallpach \& Kreuzer, 2013) to drive or inform theory development.

\section{Implications for Industrial Marketing research}

\subsection{Industrial marketing discourse and research implications}

Barry and Elmes (1997) demonstrate that rhetorical effectiveness demands both stability/credibility and novelty/change for resonant narrative constructions of strategic realities. For actors in B2B networks, balancing the novelty of newness with the credibility of existing frames to gain audience acceptance depends upon appropriate combination of use of tropes (or 'polytropy'). Contiguous 'prosaic' tropes (comparison through indexical similarity, most often between wholes and parts) such as synecdoche and metonymy are usually more effective in establishing and maintaining stability/credibility and normalizing or maintaining established realities. For example, the synecdoches of 'a network' or of 'the market' in industrial contexts are often used rhetorically as a naturalized, commonsensical 'force' to maintain an inevitable acceptance of presiding, taken-for-granted fictions of market capitalist inevitability. For these 'winning articulations', the impression is given, that there is no rhetorical alternative code or for which any novel alternative is unnatural, cognitively/discursively dissonant and, therefore, makes no sense. 


\subsection{Challenges posed for researching atmosemiospheres}

Narrative and storytelling and other aspects of discourse analysis, such as tropal analysis, provide the possibility to deal with the multiplicity of processes of perceiving, interpreting and acting that are important within interaction between actors in business network contexts (Makkonnen, Aarikka-Stenroos, \& Olkkonen, 2012). The narrative approach enables identification of relevant structural properties and contextual events, and understanding of how they steer and are reflected in the focal action (Makkonnen et al., 2012). It requires some degree of terminological plurality or 'polyphony', complexity and contextuality depending upon whichever paradigm is employed. Araujo and Easton (2012) argue that management technologies such as accounting and planning systems are an important mediating influence upon the effect of narratives. We do not dispute any of this but argue that narrative analysis in particular, and discourse analysis more generally are additionally useful and complementary approaches; particularly to existing and emerging market-making or 'shaping' approaches within B2B marketing research.

From our perspective, a bigger immediate challenge involves incorporating analysis of tropes into narrative analysis and storytelling in the exploration of networks as territories involving battles of the politics of meaning constituted through myth, folklore and fantasy. We would argue that a holistic discourse analysis, which we regard as desirable, would require a combined understanding of the interactive imagistic effect of narratives, emplotment and stories along with the role of metaphors and other tropes in discursive processes and myth-making. Ultimately, the research implication is that what we propose in terms of attention to discourse, narratives, myths, tropes and story-telling are complementary approaches to mainstream B2B marketing research that have the potential to shed more (and 
different) light on the actors, activities and resources associated with interaction in industrial networks.

\subsection{Implications for practice}

What then might be the practical implications of intertextuality, narrative and storytelling, metaphor and other tropes for networkers? The first significance for the practitioner is that tropes play an important role in establishing plots and, therefore, in the actors' capability to tell a story, which starts with knowing what kind of stories can be told. By implication, the effective networker must be a consummate moving 'picture maker' and to do so, she must have competences in narrative, emplotment, myth-making, storytelling and figuration in more than one discursive repertoire. Command of these repertoires and the consequent rhetorical capabilities through effective narration is crucial to the construction of an actors' identity through their espoused theories as a competent, practising relationship manager (Ellis \& Hopkinson, 2010; Ellis \& Ybema, 2010). Within the prevailing dominant myth of market rationalism, the 'winning articulation' is inevitably a story that will mostly involve 'optimizing customer service and maximizing profitability' in one guise or another. The capability afforded by adequate sophistry of knowing which trope to use in any particular context to secure the believability of a plot is vital in transmitting meaning and critical for the communicative effectiveness of the actor. The overall managerial implication is that the semiotic environment or semiosphere cannot be adequately managed by scientific management alone and would need complementary adaptation of methods drawn from Linguistics, Arts and Humanities - all of which support managerial 'nomadism'. Such nomadism as identified by Deleuze and Guattari (1988) involves a 'line of flight' outside of the comfort of familiar, linear reasoning into, where necessary, adoption of unfamiliar, nonlinear, creative adaptability. To cope with the contextual indeterminacy of atmosemiospheres, 
managers need to be able to adapt, in a bricolaged fashion, to the unfolding discourses with which they must deal in the moment but which they cannot control. This requires the improvisational skills of the artist rather than solely the analytical skills of the scientist. Because our message is that B2B marketers need to be more aware of (and better in) their use of tropes, narratives, and story-telling, it is somewhat difficult to provide concrete examples of how this can be done. It is not a one-size-fits-all recipe but would be a reflection of each individual actor’s situated discourse.

\section{Conclusions}

In this paper, we have examined discursive webs and how inter-connected modern myths influence what is believed within groups and how these holographic, projected images affect ideological formations and how members use them to 'see what they believe'. We have explored the complex 'atmosemiospheres' of industrial marketing research and its concomitant language games. The discursive webs on which these games are played are formed of narratives, plots and stories and metaphors and other tropes. We have argued that research cultures create and maintain meanings through web-like connotations and intertextual indirectness, which tie together the new, unknown and unexpected with the familiar fictions and myths of established received wisdoms. Our argument, therefore, is a 'business networks as discursive constructions' (Leclercq-Vandelannoitte, 2011) approach in that discursive nets, webs of narratives and stories, and labyrinths of tropes are just as important in constituting networks as more tangible aspects of networks of actor relationships and patterns of other activities and resources.

In employing a structuration theoretical perspective supported by social semiotics, we acknowledge managerialist, and interpretive approaches to discourse where agency is privileged and actors use discourse to shape theirs and others' situational understanding. 
However, we also emphasize a more critical approach that privileges structure and how agency is constituted through discourses of power-knowledge and occurs in webs of discursive structures of social domination that these structures help to legitimize and maintain (Heracleous \& Hendry, 2000). Based on structuration theory, we employ a definition of discourse as a duality constituted by two dynamically interrelated levels: the surface level of communicative action and the deeper level of discursive structures, recursively linked through the modality of actors' interpretive schemes. Surface action is configured by a topography shaped by influences from structural depths where speakers are mostly governed by structural influences but have technologies which mean that they are capable of drilling into the surface. They build surface structures to help them travel, live and sustain resources and their interpretive schemes are akin to the moderating influence between structures below and actions taken daily on the discursive planet of meaning.

Our concluding argument is that pictures of realities are socially constructed through beliefs. How beliefs form is therefore a centrally important issue. Our proposition is that belief formation is a complex process. Beliefs are multiply-layered and of different strengths. Things are believed differently in different contexts and differ in local contexts to broader contexts. They can take rational form or be constituted by myths, fantasies and other products of human imagination. Pictures always exist within a holograph. As one moves around or in and out of the holograph, the pictures change. As a result, most actors operate in an atmosemiosphere where different pictures and different sense-making reflect different beliefs and different interpretations of belief according to context. Contributing to belief formation are embodiment (sensory, perceptual, emotional), discourse (language, communication, power/knowledge) and cognition (rational and non-rational, conscious and sub-conscious). Therefore projections of different pictures in different contexts within a social holograph are filtered through a prism of interpretations. 
Discourse in this metaphor is a kind of projector of images and the light for this projector originates from narratives, stories, metaphors and other tropes and other semiotic and symbolic influences. The projector as an atmosemiosphere is consequently a significant aspect of a holographic pictured social world, in which the atmosemiosphere can be described as a 'storytelling, polysensemaking network'. Investigating this atmosemiosphere of mythologies requires examination of mutually inspiring influences of narratives, stories, metaphors and tropes and the 'intertextuality' between them. This can best be achieved when B2B researchers recognize that business environments are mutually constituted by a surface level of discursive action and a deeper level of discursive structures mediated by actors' interpretive schemes located in their practical consciousness.

Environments conceived in structuration follow the logic of the duality of agency and structure and are therefore made in discourse through action which is both a medium of structure and constituted by it. The atmosemiosphere concept illustrates how meaning is made through interaction within living business networks. To explore our understanding of the atmosemiosphere, the notion of discursive structuration was employed in order to suggest an approach capable of coping with the high degree of complexity involved. The structuration approach reveals structural and behavioural influences on outcomes as resolved mainly through discourse within situated contexts. The reflexivity required by researchers is identified as involving a realization of the situated structurational discourse processes within their own academic speech community as well as sensitivity to the differently situated structurational discourse processes of the B2B actors they are interested in understanding. 


\section{References}

Araujo, L., \& Easton, G. (2012). Temporality in business networks: The role of narratives and management technologies. Industrial Marketing Management, 41, 312-318.

Bakhtin, M.M. (1986). Speech genres and other late essays. Translated by V.W. McGee. Austin: University of Texas Press.

Barry, D., \& Elmes, M. (1997). Strategy retold: Towards a narrative view of strategic discourse. Academy of Management Review, 22, 429-452.

Barthes, R. (1972). Mythologies. Trans. A. Lavers, London, UK: Jonathan Cape.

Barthes, R. (1974). S/Z. Trans. Richard Miller. New York, NY: Noonday.

Bateson, G. (1979). Mind and nature. New York, NY: Bantam Books.

Bathurst, R.J., \& Monin, N. (2010). Finding myth and motive in language: A narrative of organizational change. Journal of Management Inquiry, 19, 262-272.

Becker, A.E. (1995). Body, self, and society: The view from Fiji. Philadelphia: University of Pennsylvania Press.

Benham, M.K.P. (2007). 'Mo'ōlelo'. In D.J. Clandinin (Ed.), Handbook of narrative enquiry: Mapping a methodology (pp. 512-533). Thousand Oaks, CA: Sage.

Bloom, P., \& Cederstom, C. (2009). The sky's the limit: Fantasy in the age of market rationality. Journal of Organizational Change Management, 22, 159-180.

Boje, D.M. (2008). Storytelling organizations. London, UK: Sage.

Bourdieu, P. (1986). "Forms of Capital" in Handbook of Theory and Research for the Sociology of Education. John G. Richardson, ed. Westport, CT: Greenwood Press, pp. 241-60.

Brown, A.D., \& Humphries, M. (2002). Narratives of organizational identity and identification: A case study of hegemony and resistance. Organization Studies, 23, 421-447.

Brown, A.D., Humphries, M., \& Gurney, P.M. (2005). Narrative, identity and change: A case study of Laskarina holidays. Journal of Organizational Change Management, 18, 312-326.

Brown, A.D., Colville, I., \& Pye, A. (2015). Making sense of sensemaking in organization studies. Organization Studies, 36, 265-277.

Cantù, C., Corsaro, D., Fiocca, R., \& Tunisini, A. (2013). IMP studies: A bridge between tradition and innovation. Industrial Marketing Management, 42, 1007-1016.

Cederlund, C.A., 2014. Think outside the box: managerial relevance and theoretical developments within B2B marketing. Journal of Business \& Industrial Marketing, 29(7/8), 642-651.

Celuch, K., Bantham, J., \& Kasouf, C. (2006). An extension of the marriage metaphor in buyer-seller relationships: An exploration of individual level process dynamics. Journal of Business Research, 59, 573-581.

Cornelissen, J.P., Oswick, C., Christensen, L.T., \& Phillips, N. (2008). Metaphor in organizational research: Context, modalities and implications for research Introduction. Organization Studies, 29, 7-22.

Cunliffe, A., \& Coupland, C. (2012). From hero to villain to hero: Making experience sensible through embodied narrative sensemaking. Human Relations, 65, 63-88.

Cunningham, M. (2007). Writer's block: failures of the neurological network and comparisons with business networks. Journal of Business \& Industrial Marketing, 22, 154-160.

Deleuze, G., \& Guattari, F. (1988). A Thousand Plateaus. London, UK: Continuum. 
Denny, R.M., \& Sunderland, P.L. (2005). Researching cultural metaphors in action: Metaphors of computing technology in contemporary U.S. life. Journal of Business Research, 58, 1456-1463.

Dwyer, R., Schurr, P., \& Oh, S (1987). Developing buyer-seller relationships. Journal of Marketing, 51, 11-27.

Edvardsson, B., Kowalkowski, C., Strandvik, T., \& Voima, P. (2014). Negative critical waves in business relationships: an extension of the critical incident perspective. Journal of Business \& Industrial Marketing, 29(4), 284-294.

Elliot, E. A., Xiao, Y., \& Wilson, E. (2015). A multicultural blend: metaphors, cognitive social capital and multiculturalism. International Marketing Review, 32(2), 200-218.

Ellis, N., \& Hopkinson, G. (2010). The construction of managerial knowledge in business networks: Managers' theories about communication. Industrial Marketing Management, 39, 413-424.

Ellis, N., \& Ybema, S. (2010). Marketing identities: Shifting circles of identification in interorganizational relationships. Organization Studies, 31, 279-305.

Fauconnier, G., \& Turner, M. (2008). Rethinking metaphor. In W. Gibbs Jr. (Ed.), The Cambridge handbook of metaphor and thought (pp. 53-66). Raymond, NY: Cambridge University Press.

Ford, D., Gadde, L., Håkansson, H., \& Snehota, I. (2003). Managing business relationships. Chichester, UK: Wiley.

Ford, D., \& Håkansson, H. (2006). IMP - Some things achieved: Much more to do. European Journal of Marketing, 40, 248-258.

Ford D., Håkansson, H, Gadde, L.E., Snehota I., \& Waluszewski, A. (2009). Analysing business interaction. The IMP Journal, 4, 86-103.

Ford, D., \& Håkansson, H. (2013). Competition in business networks. Industrial Marketing Management, 42, 1017-1024.

Ford, D., \& Redwood, M. (2005). Making sense of network dynamics through network pictures: A longitudinal case study. Industrial Marketing Management, 34, 648-657.

Ford, D., \& Saren, M. (1996). Technology strategy for business. Andover, UK: Cengage Learning.

Foucault, M. (1997). The masked philosopher. In P. Rabinow, (Ed.), Ethics. The essential works, 1, (pp. 321-328). London, UK: Penguin.

Freidrich, P. (1991). Polytropy. In J. Fernandez (Ed.), Beyond metaphor: The theory of tropes in anthropology (pp. 17-55). Stanford: Stanford University Press.

Fuller, T., \& Lewis, J. (2002). 'Relationships mean everything': A typology of small-business relationship strategies in a reflexive context. British Journal of Management, 13, 317336.

Gabriel, Y. (2000). Storytelling in organizations: Facts, fictions, fantasies. Oxford, UK: Oxford University Press.

Gabriel, Y. (2004). Myths, stories and organizations: Premodern narratives for our times. New York, NY: Oxford University Press.

Gabriel, Y., Geiger, D., \& Letiche, H. (2011). The marriage of story and metaphor. Culture and Organization, 17, 367-371.

Geertz, C. (1973). The interpretation of cultures: Selected essays (Vol. 5019). New York, NY: Basic Books.

Geiger, D., \& Antonacopoulou, E. (2011). Narratives and organizational dynamics: Exploring blind spots and organizational inertia. Journal of Applied Behavioural Science, 45, 411-436. 
Geiger, S., \& Finch, J. (2010). Networks of minds and networks of organizations: The map metaphor in business network research. Industrial Marketing Management, 39, 381389.

Giddens, A. (1984). The constitution of society: Outline of the theory of structuration. Cambridge, MA: Polity.

Grant, D., \& Hardy, C. (2004). Introduction: Struggles with organizational discourse. Organization Studies, 25, 5-13.

Håkansson, H., \& Ford, D. (2002). How should companies interact in business networks? Journal of Business Research, 55, 133-139.

Håkansson, H., \& Waluszewski, A. (2013). A never ending story: Interaction patterns and economic development. Industrial Marketing Management, 42, 443-454.

Hedaa, L., \& Törnroos, J.Å. (2007). Atmospheric disturbances in the IMP interaction model: Introducing semiosphere into business interaction. Competitive paper for the $23^{\text {rd }}$ IMP Conference, Manchester, UK.

Henneberg, S., Naudé, P., \& Mouzas, S. (2010). Sense-making and management in business networks - some observation, considerations, and a research agenda. Industrial Marketing Management, 39, 355-360.

Heracleous, L., \& Hendry, J. (2000). Discourse and the study of organization: Toward a structurational perspective. Human Relations, 53, 1251-1286.

Hodge, R. I. V. (1988). Social semiotics. Cornell University Press.

Holbrook, M.B. (2005). Customer value and autoethnography: Subjective personal introspection and the meanings of a photograph collection. Journal of Business Research, 58, 45-61.

Hunt, S., \& Menon, A. (1995). Metaphors and competitive advantage: Evaluating the use of metaphors in theories of competitive strategy. Journal of Business Research, 33, 8190.

Ivanova-Gongne, M. (2015). Culture in business relationship interaction: an individual perspective. Journal of Business \& Industrial Marketing, 30(5), 608-615.

Jian, G. (2011). Articulating circumstance, identity and practice: Toward a discursive framework of organizational changing. Organization, 18, 45-64.

Johnston, W., \& Hausman, A. (2006). Expanding the marriage metaphor in understanding long-term business relationships. Journal of Business \& Industrial Marketing, 21, 446-452.

Kjellberg, H., \& Helgesson, C-F. (2006). Multiple versions of markets: Multiplicity and performativity in market practices. Industrial Marketing Management, 35, 839-855.

Kjellberg, H., \& Helgesson, C-F. (2007). On the nature of markets and their practices. Marketing Theory, 7, 137-162.

Kress, G. (2009). Multimodality: A social semiotic approach to contemporary communication. Routledge.

Kress, G. and Van Leeuwen, T. (2001) Multimodal Discourse - The Modes and Media of Contemporary Communication. London: Arnold

Kronberger, M., Clegg, S., \& Carter, C. (2006). Rethinking the polyphonic organization: Managing as discursive practice. Scandinavian Journal of Management, 22, 3-30.

Küpers, W.M. (2013). Embodied transformative metaphors and narratives in organisational life-worlds of change. Journal of Organizational Change Management, 26, 494-528.

Leclercq-Vandelannoitte, A. (2011). Organizations as discursive constructions: A Foucauldian approach. Organization Studies, 32, 1247-1271.

Lowe, S., Ellis, N., \& Purchase, S. (2008). Rethinking language in IMP research: Networking processes in other words. The Scandinavian Journal of Management, 24, 296-307. 
Lowe, S., Ellis, N., Purchase, S., Rod, M., \& Hwang, K-S. (2012). Mapping alternatives: A commentary on Cova, B., et al. (2010) 'Navigating between dyads and networks'. Industrial Marketing Management, 41, 357-364.

Lowe, S., Purchase, S., \& Ellis, N. (2012). The dramaturgy of business networks. Industrial Marketing Management, 41, 421-428.

Makkonnen, H., Aarikka-Stenroos, L., \& Olkkonen, R. (2012). Narrative approach in business network process research - Implications for theory and methodology. Industrial Marketing Management, 41, 287-299.

Martin, D. (2010). Uncovering unconscious memories and myths for understanding international tourism behaviour. Journal of Business Research, 63, 372-383.

Martin, D., \& Woodside, A.G. (2011). Gestalt modeling of international tourism behavior: Applying dimensional qualitative research in constructing grounded theory. Psychology \& Marketing, 28, 998-1026.

Morgan, G. (1986). Images of organization. Thousand Oaks, CA: Sage Publications.

Mouzas, S., Henneberg, S., \& Naudé, P. (2008). Developing network insight. Industrial Marketing Management, 37, 167-180.

Mumby, D. (1987). The political function of narrative in organizations. Communication Monographs, 54, 113-127.

Munro, I., \& Huber, C. (2012). Kafka's mythology: Organization, bureaucracy and the limits to sensemaking. Human Relations, 65, 523-544.

Nicolini, D. (2009). Zooming in and out: Studying practices by switching theoretical lenses and trailing connections. Organization Studies, 30, 1391-1418.

O’Malley, L., Patterson, M., \& Kelly-Holmes, H. (2008). Death of a metaphor: Reviewing the 'marketing as relationships' frame. Marketing Theory, 8, 167-187.

Potter, J., \& Wetherell, M. (1987). Discourse in social psychology. London, UK: Sage.

Putnam, L.L. (2004). Dialectical tensions and rhetorical tropes in negotiations. Organization Studies, 25, 35-53.

Raskovic, M. (2015). Economic sociology and the ARA interaction model. Journal of Business \& Industrial Marketing, 30(5), 472-485.

Riad, S. (2011). Terms of engagement: On the differential effects of metaphoric utterances in relational stories of organization. Culture and Organization, 17, 373-388.

Rinallo, D., \& Golfetto, F. (2006). Representing markets: The shaping of fashion trends by French and Italian fabric companies. Industrial Marketing Management, 35, 856-869.

Ritter, T., Wilkinson, I.F., \& Johnston, W.J. (2004). Managing in complex business networks. Industrial Marketing Management, 33, 175-183.

Ryynänen, H., Henttonen, K., \& Salminen, R. T. (2015). Inter-organizational cognitive structures: network conception in MobileTV case. Journal of Business \& Industrial Marketing, 30(5), 662-676.

Stoltman, J., \& Morgan, F. (2002). Extending the marriage metaphor as a way to view marketing relationships. Journal of Business-to-Business Marketing, 9, 49-75.

Tannen, D. (2010). Abduction and identity in family interaction: Ventriloquizing as indirectness. Journal of Pragmatics, 42, 307-316.

Thibault, P. (1991). Social semiotics as praxis. Minneapolis: University of Minnesota.

Todd, P.R., Javalgi, R.G., \& Grossman, D. (2014). Understanding the characteristics of the growth of SMEs in B-to-B markets in emerging economies: an organizational ecology approach. Journal of Business \& Industrial Marketing, 29(4), 295-303.

Van Leeuwen, T. (2005). Introducing social semiotics. Psychology Press. Chicago

Von Wallpach, S., \& Kreuzer, M. (2013). Multi-sensory sculpting (MSS): Eliciting embodied brand knowledge via multi-sensory metaphors. Journal of Business Research, 66, 1325-1331. 
Watson, T. J. (1995). Rhetoric, discourse and argument in organizational sense making: A reflexive tale. Organization Studies, 16, 805-821.

Wilkinson, I., \& Young, L. (1994). Business dancing - The nature and role of inter-firm relations in business strategy. Asia-Australia Journal of Marketing, 2, 67-79.

Wilkinson, I., Young, L., Welch, D., \& Welch, L. (1998). Dancing to success: Export groups as dance parties and the implications for network development. Journal of Business \& Industrial Marketing, 13, 492-510.

Woodside, A.G. (2006). Overcoming the illusion of will and self-fabrication: Going beyond naïve subjective personal introspection to an unconscious/conscious theory of behavior explanation. Psychology and Marketing, 23, 257-272.

Woodside, A.G. (2008). Using the forced metaphor-elicitation technique (FMET) to meet animal companions within self. Journal of Business Research, 61, 480-487.

Zaltman, L. (2008). Comment on "Using the forced metaphor-elicitation technique (FMET) to meet animal companions within self”. Journal of Business Research, 61, 488-489. 
TABLE 1: Comparative Summary Of Established Industrial Network (Atmospheric) Versus Social Semiotic Perspectives

\begin{tabular}{|c|c|c|}
\hline & Atmospheric & (Atmo-)Semiospheric \\
\hline Relationship ENVIRONMENT & $\begin{array}{l}\text { Relationships through } \\
\text { interaction embedded within } \\
\text { 'atmosphere', which involves } \\
\text { tacit sentiments, dispositions } \\
\text { and assumptions held by actors. }\end{array}$ & $\begin{array}{l}\text { Relationships through Signs constituted by associations and } \\
\text { analogues between signifiers and signified together constitute } \\
\text { projected images and symbols that configure subsequent } \\
\text { interpretations and meanings between actors }\end{array}$ \\
\hline Action / Cognition & Causal & Structurational \\
\hline Structural Relations & Linear / Structural & Non-Linear/ Processual \\
\hline Focus & Actors, Activities, Resources & $\begin{array}{l}\text { Meaning / Hermeneutics: } \\
\text { Actor-Actants, Symbolic Identities } \\
\text { Activities-Signification of Action } \\
\text { Resources-Symbols from Artefacts }\end{array}$ \\
\hline Ontology & Realist & Nominalist \\
\hline Epistemic Purpose & Nomothetic Theorizing & Context Specific Ideographic Description \\
\hline Emphasis & Cognition & Embodiment, Discourse, Cognition \\
\hline $\begin{array}{l}\text { Social construction principally } \\
\text { through.......... }\end{array}$ & Rationality between Agents & Mythologizing amongst Agents \\
\hline
\end{tabular}

